\title{
Chloroquine Protects Human Corneal Epithelial Cells from Desiccation Stress Induced Inflammation without Altering the Autophagy Flux
}

\author{
Shivapriya Shivakumar, ${ }^{1}$ Trailokyanath Panigrahi, ${ }^{1}$ Rohit Shetty, ${ }^{2}$ Murali Subramani, \\ Arkasubhra Ghosh $\mathbb{D}^{1}{ }^{1}$ and Nallathambi Jeyabalan $\mathbb{D}^{1}$ \\ ${ }^{1}$ GROW Research Laboratory, Narayana Nethralaya Foundation, Bangalore, Karnataka, India \\ ${ }^{2}$ Department of Cornea and Refractive surgery, Narayana Nethralaya Eye Hospital, Narayana Health City, \\ Bommasandra, Bangalore, Karnataka, India \\ Correspondence should be addressed to Arkasubhra Ghosh; arkasubhra@narayananethralaya.com \\ and Nallathambi Jeyabalan; drnallathambi@narayananethralaya.com
}

Received 19 April 2018; Revised 21 August 2018; Accepted 1 October 2018; Published 1 November 2018

Academic Editor: Arianna Scuteri

Copyright (C) 2018 Shivapriya Shivakumar et al. This is an open access article distributed under the Creative Commons Attribution License, which permits unrestricted use, distribution, and reproduction in any medium, provided the original work is properly cited.

\begin{abstract}
Dry eye disease (DED) is a multifactorial ocular surface disorder affecting millions of individuals worldwide. Inflammation has been associated with dry eye and anti-inflammatory drugs are now being targeted as the alternate therapeutic approach for dry eye condition. In this study, we have explored the anti-inflammatory and autophagy modulating effect of chloroquine (CQ) in human corneal epithelial and human corneal fibroblasts cells exposed to desiccation stress, (an in-vitro model for DED). Gene and protein expression profiling of inflammatory and autophagy related molecular factors were analyzed in HCE-T and primary HCF cells exposed to desiccation stress with and without CQ treatment. HCE-T and HCF cells exposed to desiccation stress exhibited increased levels of activated p65, TNF- $\alpha$, MCP-1, MMP-9, and IL-6. Further, treatment with CQ decreased the levels of active p65, TNF- $\alpha$, MCP-1, and MMP-9 in cells underdesiccation stress. Increased levels of LC3B and LAMP1 markers in HCE-T cells exposed to desiccation stress suggest activation of autophagy and the addition of CQ did not alter these levels. Changes in the phosphorylation levels of MAPKinase and MTOR pathway proteins were found in HCE-T cells under desiccation stress with or without CQ treatment. Taken together, the data suggests that HCE-T cells under desiccation stress showed NF $\kappa B$ mediated inflammation, which was rescued through the anti-inflammatory effect of CQ without altering the autophagy flux. Therefore, CQ may be used as an alternate therapeutic management for dry eye condition.
\end{abstract}

\section{Introduction}

Dry eye disease (DED) is characterized by an abnormal instability of the tear film leading to ocular discomfort, visual disturbance, inflammation, dryness, and irritation of the eye [1]. Inflammation is a primary response of one's body towards stress and foreign substances; it is a major risk factor for several chronic diseases including dry eye. Recent studies have reported that inflammation associated with dry eye was mediated by T-lymphocytes [2]. Dry eye patients were found with higher levels of proinflammatory cytokines such as IL1 $\alpha$ [3] along with IL-1 $\beta$, IL-6, IL-8, and tumor necrosis factor (TNF- $\alpha$ ) in the tear film compared to normal controls [4]. Chloroquine (CQ), a widely known antimalarial drug has been used as an anti-inflammatory agent for treating rheumatoid arthritis [5] and discoid lupus erythematosus [6]. Studies have shown that CQ inhibits the release of pro-inflammatory cytokines in the human blood during chronic and bacteria-induced inflammation [7]. CQ blocks TNF- $\alpha$ and IL- 6 synthesis in lipopolysaccharide (LPS) stimulated inflammation in mouse macrophages. It was also been found to inhibit LPS-induced activation of TNF- $\alpha$ \& ERK1/2 gene expression in PBMC's [8]. In addition to its anti-inflammatory activity CQ is a known modulator of autophagy. Autophagy is a cellular mechanism through which damaged intracellular molecules and organelles are cleared 
through the autophagic lysosomal pathway. It is activated during stress and starvation, thereby allowing cells to survive in response to various stresses [9]. Autophagy has been implicated in a number of fundamental biological processes including aging, immunity, inflammation, development, and differentiation [10]. Studies have reported higher doses of CQ with prolonged oral administration leading to retinal toxicity, with decreased visual acuity, diplopia, and bilateral vision loss [11], and other additional side effects such as ototoxicity, seizures, insomnia, and paresthesia [12]. Anti-inflammatory drugs like cyclosporine and chloroquine are widely being used as alternate therapy for dry eye condition. Clinical application of CQ showed anti-inflammatory effect through the improvement in immunoglobulin levels and erythrocyte sedimentation rate (ESR) and decrease in inflammatory cytokines in primary Sjogren's syndrome (pSS). However, the clinical efficacy was is moderate in keratoconjunctivitis sicca syndrome $[13,14]$.

In spite of the known anti-inflammatory and autophagy modulating activity of CQ, its modulation on ocular surface disease mechanisms has not been explored. In addition, studies have shown that inflammation and autophagy are interdependent process [15], but the underlying mechanisms still remain unclear. Therefore, to explore the therapeutic effect of CQ in the pathogenesis of dry eye condition, we subjected primary human corneal epithelial cells, HCE-T cells, and corneal fibroblast (HCF) cells to desiccation stress (experimental condition for dry eye) and analysed the antiinflammatory and autophagy modulating activity of CQ. Several studies have shown direct association and increased expression levels of inflammatory cytokines IL-6, TNF- $\alpha$ [16], MCP-1 [17], and MMP-9 in tears of dry eye patients. Hence, we are interested in studying the effect of CQ on the above cytokines levels in in-vitro experimental conditions for dry eye disease.

\section{Materials and Methods}

2.1. Viability Assay for HCE Cells Treated with CQ. HCE-T cells were treated with different concentrations (0.00006 to $0.003 \%$ ) of CQ for 48 hrs. Tryphan blue assay was used to determine the cell viability.

\subsection{Immunofluorescence Staining. HCE-T cells were cultured} on chamber slides at density of $0.1 \times 10^{6}$ cells/well. After 24 hours the media were removed and cells were fixed with $100 \%$ ice cold methanol for 5 minutes at room temperature. Further, cells were treated with permeabilization buffer containing 1XPBS and $0.1 \%$ triton X-100. Cells were then blocked with $3 \%$ bovine serum albumin (BSA) at room temperature for 30 minutes, followed by incubation with primary cytokeratin 3 antibody (abcam, Cat no- ab77869) (1:500) overnight at 4 degree. Alexa fluor 488- conjugated anti-mouse secondary antibody (abcam, Cat no- ab150113) was used (1:2000) and kept for 1 hour incubation at room temperature. Finally the cells were mounted using fluoroshield

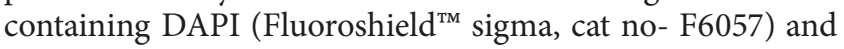
examined under fluorescence microscope using FL1 and FL2 channels.
2.3. Cell Culture and Desiccation Stress. Primary human corneal epithelial cells (HCE) of limbal origin were derived from donor corneal tissues and cultured according to the protocol [18]. Human corneal fibroblasts (HCF) cells were derived from donor corneal buttons by following previously mentioned protocol [19]. SV40 large T antigen immortalized human corneal epithelial cell line (HCE-T) and HCF cells (passage 3 ) were cultured at the density of $0.3 \times 10^{6}$ cells/well in a growth medium (DMEM/F-12, Gibco, USA) containing $5 \%$ and $20 \%$ fetal bovine serum (Gibco, USA), $100 \mathrm{U} / \mathrm{ml}$ penicillin, and $100 \mathrm{mg} / \mathrm{ml}$ streptomycin sulphate (SigmaAldrich, St. Louis, MO) at $37^{\circ} \mathrm{C}$. To induce desiccation stress, the media were completely aspirated from primary HCE, HCF, and HCE-T cells and air dried for 10 minutes at room temperature $\left(25^{\circ} \mathrm{C}\right)$ and humidity of $(40 \%)$. Further, the growth media were replenished and cells were treated with $0.03 \%$ chloroquine (CQ- UV LUBE UNIMS - FDC Ltd., India) $(5 \mu \mathrm{l} / \mathrm{ml}$ ) and Restasis $0.05 \%$ (CsA - Cyclosporine ophthalmic emulsion, Allergan, Pvt. Ltd, India) $(2 \mu \mathrm{l} / \mathrm{ml})$. After 24 hrs, HCE-T cells and primary HCE and HCF cells exposed to desiccation stress were evaluated for morphology and viability using light microscopy and trypan blue assays, respectively.

2.4. RNA Isolation and $q P C R$ Analysis. Total RNA was extracted from HCE-T and HCF cells exposed to desiccation stress, treated with and without CQ/CsA using Trizol reagent (Invitrogen, USA). RNA was quantified using a nanodrop spectrophotometer (NanoDrop 1000, Thermo Scientific, DE, USA). 1000 ng of the total RNA was converted to cDNA using Biorad iScript ${ }^{\mathrm{TM}} \mathrm{cDNA}$ synthesis kit. Quantitative real-time PCR was performed using $4 \mu \mathrm{l}$ of 10 -fold diluted cDNA in a final volume of $10 \mu \mathrm{l}$ using the SYBR Green master mix (BioRad, Philadelphia, PA, USA). Gene expression profile was studied for inflammatory and autophagy related genes- IL6, TNF- $\alpha$, MCP-1, MMP-9, LC3A, LC3B, LAMP1, and ATG7. The primer sequences used are mentioned in Table 1. All data was analyzed by $\Delta \Delta \mathrm{Ct}$ method and the mRNA of beta-actin was used as the internal standard.

2.5. Protein Extraction and Western Blot Analysis. Whole cell protein lysate and nuclear-cytoplasmic fractions were extracted from HCE-T and HCF cells exposed to desiccation stress, treated with and without CQ/CsA using RIPA lysis buffer and nuclear/cytoplasmic extraction kit respectively (Cat no-786-489 and 786-182, G-Biosciences, USA). Protease and phosphatase inhibitors [(phosphostop cat no0490687001, cOmplete EDTA free protease inhibitor cocktail (Cat no-04693159001, Roche life science, USA)] were added to the extraction buffers. The cells were snap frozen and thawed twice followed by vortexing for $30 \mathrm{sec}$ which was repeated five times. The lysate was centrifuged at $13000 \mathrm{rpm}$ for 20 minutes at $4^{\circ} \mathrm{C}$. Protein concentration was measured using Bradford reagent (Cat no-5000006, Biorad, USA). $20 \mu \mathrm{g}$ of protein was loaded \& run on $10 \%$ SDS PAGE, blotted onto PVDF membrane and blocked with 5\% milk powder in TBST for $\mathrm{hr}$ at room temperature. All primary antibodies were incubated overnight in dark at 4 degree: p65 [1:1000, Cell Signaling-C20], P-p65 (Ser536) [1:1000, Cell 
TABLE 1: Primers used for quantitative-qPCR analysis.

\begin{tabular}{|c|c|c|}
\hline Gene Name & Sequences $\left(5^{\prime}-3^{\prime}\right)$ & Gene acc no \\
\hline LC3A & $\begin{array}{l}\text { FP: CGTCCTGGACAAGACCAAGT } \\
\text { RP: CTCGTCTTTCTCCTGCTCGT }\end{array}$ & NM_032514 \\
\hline LC3B & $\begin{array}{l}\text { FP:AGCAGCATCCAACCAAAATC } \\
\text { RP:CTGTGTCCGTTCACCAACAG }\end{array}$ & NM_022818 \\
\hline LAMP1 & $\begin{array}{l}\text { FP: AGTGGCCCTAAGAACATGACC } \\
\text { RP: } \\
\text { AGTGTATGTCCTCTTCCAAAAGC }\end{array}$ & NM_005561 \\
\hline MMP9 & $\begin{array}{l}\text { FP: GGGCTTAGATCATTCCTCAGTG } \\
\text { RP: GCCATTCACGTCGTCCTTAT }\end{array}$ & NM_004994 \\
\hline LOX & $\begin{array}{l}\text { FP: ACATTCGCTACACAGGACATC } \\
\text { RP: TTCCCACTTCAGAACACCAG }\end{array}$ & NM_002317 \\
\hline IL6 & $\begin{array}{l}\text { FP: } \\
\text { GATGAGTACAAAAGTCCTGATCCA } \\
\text { RP: CTGCAGCCACTGGTTCTGT }\end{array}$ & NM_54894 \\
\hline ATG7 & $\begin{array}{l}\text { FP: GGA TGA AGC TCC CAA GGA } \\
\text { CAT } \\
\text { RP: CCA GCA GAG TCA CCA TTG } \\
\text { TAG TA } \\
\end{array}$ & NM_001144912 \\
\hline TNF- $\alpha$ & $\begin{array}{l}\text { FP: CAGCCTCTTCTCCTTCCTGAT } \\
\text { RP: GCCAGAGGGCTGATTAGAGA }\end{array}$ & NM_000594 \\
\hline$\beta$ ACTIN & $\begin{array}{l}\text { FP: GCCAACCGCGAGAAGATGA } \\
\text { RP: CCATCACGATGCCAGTGGTA }\end{array}$ & NM_001101 \\
\hline
\end{tabular}

Signaling-(93H1)], $\mathrm{I} \kappa \mathrm{B} \alpha$ [1:1000, Cell Signaling (L35A5)], LAMP1 [1:1000, Cell Signaling (D2D11) XP], LC3A/B [1:1000, Cell Signaling, (\#4108)], SQSTM1/p62 [1:1000,Cell Signaling (\#5114)], p38 [1:1000, Cell signalling (\#9202)], P-p38 (Thr180/Thy182) [1:1000, Cell Signaling (3D7)], p70S6Kinase [1:1000, Cell Signaling (9202)], P-p70S6Kinase (Thy389) [1:1000, Cell Signaling (9205)], ERK1/2 [1:1000, Cell signalling (137F5)], P-ERK1/2 (Thr180/Thy204) [1:1000, Cell signalling (D13.14.4E)], Akt [1:1000, Cell Signaling (4691)], P-Akt (Ser473) [1:1000, Cell Signaling (9271)], Beclin-1 [1:1000, Cell signalling (D40C5)] $\beta$ - actin [1:3000, Santa Cruz, C-4], and GAPDH [1:2000, Abgenex, Clone:ABM22C5]. The secondary antibodies (anti-rabbit, anti-mouse) were conjugated with horseradish peroxidase and a chemiluminescence substrate (Biorad, Philadelphia, PA, USA) to visualize the band (Image Quant LAS 500, GE Healthcare, Life Sciences, USA).

2.6. Transfection. HCE-T cells were cultured in chamber slide at a density of 10000 cells/well and transfected with GFP-RelA plasmid (Addgene, Plasmid \#23255) using Xfect ${ }^{\mathrm{TM}}$ transfection reagent (Cat no- 631317, Clontech, Takara, USA.) as per manufacturer's protocol. After $24 \mathrm{hrs}$, cells were exposed to desiccation stress followed by treatment with and without CQ/CsA. TNF- $\alpha$ ((10 ng/ml); Cat no-654205, Calbiochem, Merk, Germany) was used as a positive control to observe the GFP-RelA nuclear translocation. The localisation of GFPRelA in HCE-T cells exposed to desiccation stress withand without CQ/CsA treatment was analysed under fluorescence microscope (EVOS -FL- Auto Cell Imaging System, Thermo fisher Scientific, USA).

2.7. Fluorescence Staining. HCE-T cells were cultured on $0.3 \%$ gelatin coated cover slips at a density of $0.3 \times 10^{6}$ cells/well.
Then cells were exposed to desiccation stress, treated with and without CQ/CsA. Cells were then incubated with CYTO-ID and Lysotracker dye (LTR) to quantify autophagosome and lysosomes followed by the method as described previously [20]. The lysosomal pH of HCE-T cells exposed to desiccation stress was assessed using acridine orange dye. Cells were fixed with $4 \%$ paraformaldehyde and examined under fluorescence microscope.

2.8. Statistical Analysis. Experiments were performed three independent times and the data are represented as a mean \pm $\mathrm{SD}(\mathrm{n}=3)$. One way ANOVA followed by Dunnett's multiple analysis was performed using Graphpad prism software version 6 . The level of significance is represented as $\left({ }^{*} \mathrm{P}<0.05\right.$, ${ }^{* *} \mathrm{P}<0.01$, and $\left.{ }^{* * *} \mathrm{P}<0.001\right)$.

\section{Results}

3.1. Cytotoxic Activity of CQ on HCE Cells. HCE-T cells treated with different concentrations of CQ (0.00006 to $0.003 \%)$ for $48 \mathrm{hrs}$ were analysed for cell viability using trypan blue dye. The cells treated with $0.00006 \%$ of CQ showed 3\% cell death and $80-84 \%$ was observed at $0.003 \%$ (Supplementary figure 1).

3.2. Cytokeratin 3 Staining in HCE Cells. Immunostaining of cytokeratin 3 in HCE-T cells showed presence of green fluorescence in the cytoplasm region, with the typical sign of filamentous staining emerging from the nucleus towards the cell membrane (Supplementary figure 2).

3.3. HCE and HCF Cells under Desiccation Stress. HCE$\mathrm{T}$ cells, primary HCF, and HCE cells under desiccation 
stress showed changes in morphology (shape and size) with reduction in cell viability. HCE-T cells exposed to desiccation stress showed a reduced cell viability of (80-85\%) at 24 hours compared to non-desiccated cells. Desiccated cells treated with CQ showed (92-94\%) and CsA (88-90\%) viability with no significant morphological changes were noted at 24 hrs (Figures 1(a) and 1(b)). In addition, HCF cells with desiccation stress showed a viability of (75-80\%) at 24 hours compared to non-desiccated cells and cells treated with CQ (84-86 \%) and CsA showed viability (80-83\%) (Figures 1(c) and $1(\mathrm{~d})$ ). Further, primary HCE cells under desiccation stress showed a reduction in viability of (69-73\%) at 24 hours compared non-desiccated cells. Further, cells treated with CQ and CsA showed a percentage of viability of $85-90 \%$ and $83-87 \%$ in comparison with desiccated cells alone (Figures $1(\mathrm{e})$ and $1(\mathrm{f}))$.

3.4. CQ Reduces Desiccation Stress Induced Inflammation in HCE and HCF Cells. HCE-T and HCF cells under desiccation stress with and without CQ, CsA treatment were analyzed for the expression of inflammation related genes IL6, TNF$\alpha$, MCP-1, and MMP-9 by using qPCR. The mRNA levels of IL6, TNF- $\alpha$, MCP-1, and MMP-9 were increased in HCE$\mathrm{T}$ and HCF cells exposed to desiccation stress compared to control (Figures 2(a) and 2(c)). In addition, cells treated with CQ and CsA showed decrease in levels of TNF- $\alpha$, MCP-1, and MMP-9 compared to desiccated cells. Western blotting was carried out to analyse the activation status of p65 (phosphorylation at ser536). An increased phosphorylation level of p65 was observed in desiccated cells compared to control (Figures 2(b) and 2(d)). Further, cells treated with CQ and CsA showed decrease in phosphorylation levels of p65 in comparison to desiccated cells (Figures 2(b) and 2(d)).

\subsection{Regulation of NFאB Pathway by CQ in HCE-T Cells} under Desiccation Stress. The NFkB pathway regulation by CQ was analysed in nuclear/cytoplasmic fractions of HCE$\mathrm{T}$ cells subjected to desiccation stress. The results revealed an increased p65 level in nuclear compared to the cytoplasmic fraction in HCE-T cells exposed to desiccation stress (Figure 3(a)). In contrast, HCE-T cells treated with CQ and CsA showed increased retention of p65 in cytoplasm compared to desiccated cells without treatment. Further, the cytoplasmic $\mathrm{I} \kappa \mathrm{B} \alpha$ levels in HCE-T cells exposed to desiccation stress with and without CQ/CsA treatment were analysed by western blotting (Figure 3(a)). Desiccated cells showed decreased $\mathrm{I} \kappa \mathrm{B} \alpha$ levels compared to control. Whereas, desiccated cells treated with $\mathrm{CQ}$ exhibited higher levels of $\mathrm{I} \kappa \mathrm{B} \alpha$ compared to desiccated cells (Figure 3(a)). These results were further confirmed by monitoring GFP-RelA (p65) nuclear translocation in HCE-T cells exposed to desiccation stress with and without CQ and CsA treatment. Desiccated/TNF- $\alpha$ treated cells showed increased GFP-RelA nuclear translocation compared to control (Figure 3(b)). Besides, treatment with CQ/CsA showed reduced or partial levels of GFPRelA nuclear translocation compared to desiccated cells (Figure 3(b)).
3.6. Induction of Autophagy in HCE-T Cells Exposed to Desiccation Stress. HCE-T cells exposed to desiccation stress with and without CQ/CsA treatment was analysed for autophagy related markers by measuring the levels of mRNA, protein, autophagosomes and lysosomes. The mRNA expression level of autophagosomal marker LC3A was significantly higher in desiccated cells compared to control, whereas there were no changes in the levels of LC3B, ATG7, and LAMP1(lysosomal marker) (Figure 4(a)). Further, cells treated with CQ/CsA showed increase in levels of LC3B, ATG7 and LAMP1 compared to desiccated cells (Figure 4(a)). Western blotting showed an increase in the expression levels of LC3B and p62 with no changes in the LAMP1 levels in HCE-T cells exposed to desiccation stress compared to control (Figure 4(b)). Cells treated with CQ showed increase in LC3B and LAMP1 levels compared to desiccated cells, whereas HCE$\mathrm{T}$ treated with CsA showed increased levels of LAMP1 and p62 with decreased levels of LC3B compared to desiccated cells (Figure 4(b)). These results were further confirmed by Cyto-ID and Lysotracker red (LTR) which were used to monitor the levels of autophagosomes and lysosomes in HCE-T cells exposed to desiccation stress with andwithout CQ/CsA treatment. Increased levels of autophagosomes (green fluorescence) and lysosomes (red fluorescence) were observed in HCE-T cells exposed to desiccation stress compared to control in the perinuclear regions (Figures 5(a) and 5(b)). Additionally, desiccated cells treated with CQ showed an increased number of autophagosome and lysosome, but treatment with CsA did not show any significant changes in autophagosome/lysosome levels. Acridine orange dye was used to analyse intracellular lysosome $\mathrm{pH}$ in HCE-T cells exposed to desiccation stress. It was observed that desiccated cells showed change in lysosomal $\mathrm{pH}$ compared to control (red to green shift). CQ and CsA were able to maintain the $\mathrm{pH}$ in comparison to desiccated cells (Figure 5(c)).

3.7. Analysis of the Effect of CQ on Signalling Pathways Associated with Desiccation Stress. To elucidate the pathways regulated by CQ in HCE-T cells under desiccation stress, immunoblotting was performed for evaluating the phosphorylation levels of MAPKinase, AKT/p70S6kinases and AMPK proteins. HCE-T cells under desiccation stress showed increased phosphorylation levels of ERK1/2 at Thr180/Thy204 and p38 (Thr180/Thy182) proteins (Figure 6), along with a decrease in the phosphorylation levels of AKT (Ser473) and p70S6kinase (Thy389) compared to control. Interestingly, treatment with CQ/CsA decreased the phosphorylation levels of ERK1/2 (Thr180/Thy204) and p38 (Thr180/Thy182), along with an increase in phosphorylation of levels AKT (Ser473)/p70S6kinase (Thy389), compared to desiccated cells (Figure 6).

\section{Discussion}

In the present study, HCE and HCF cells exposed to desiccation stress were used as an experimental model for studying the pathogenesis dry eye disease. The therapeutic effect of $\mathrm{CQ}$ in human corneal cell types exposed to desiccation 


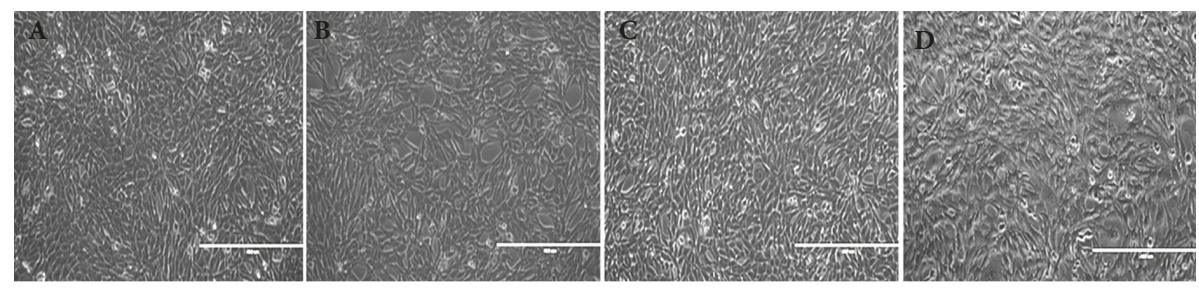

(a)

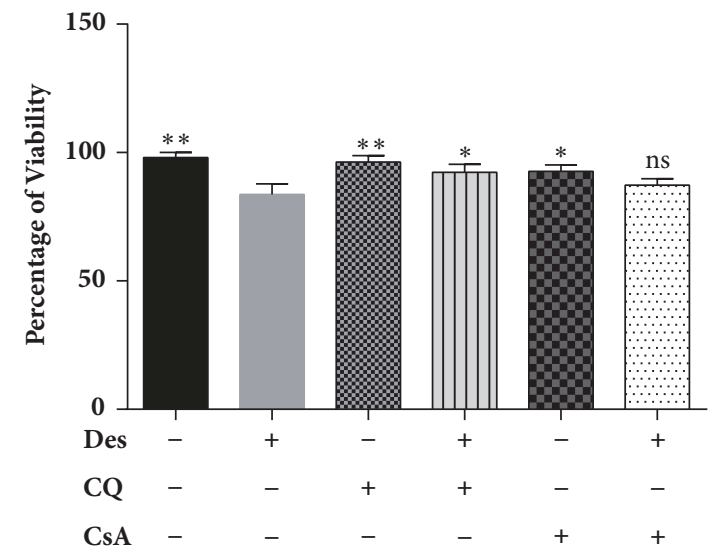

(b)
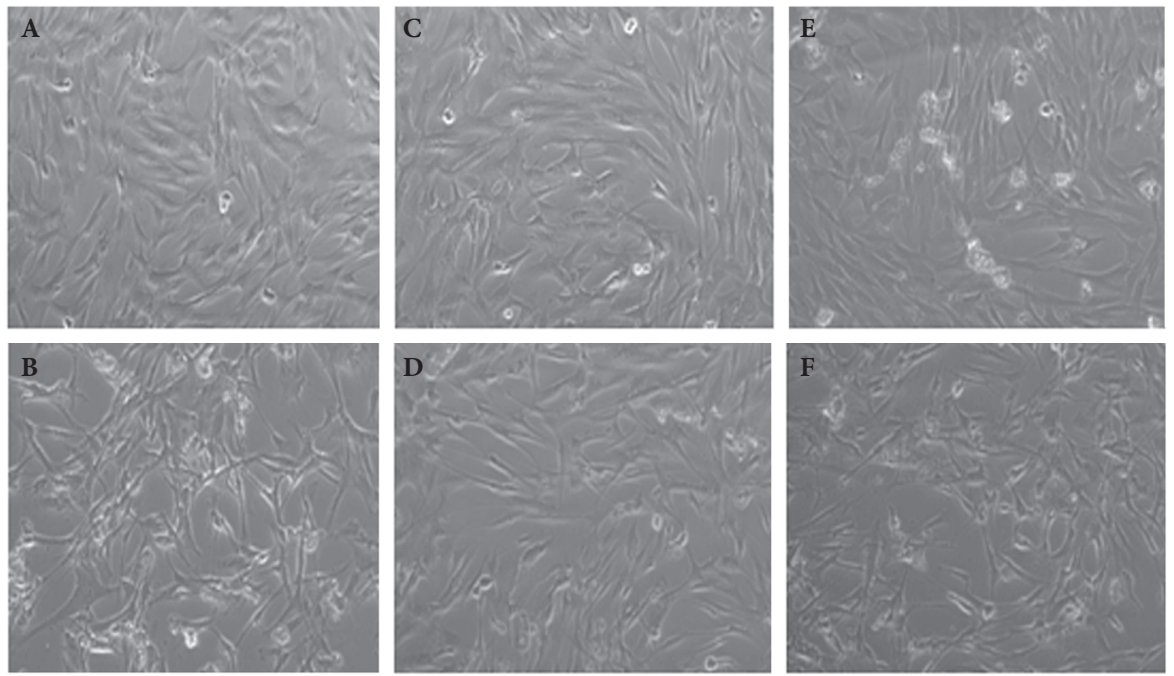

(c)

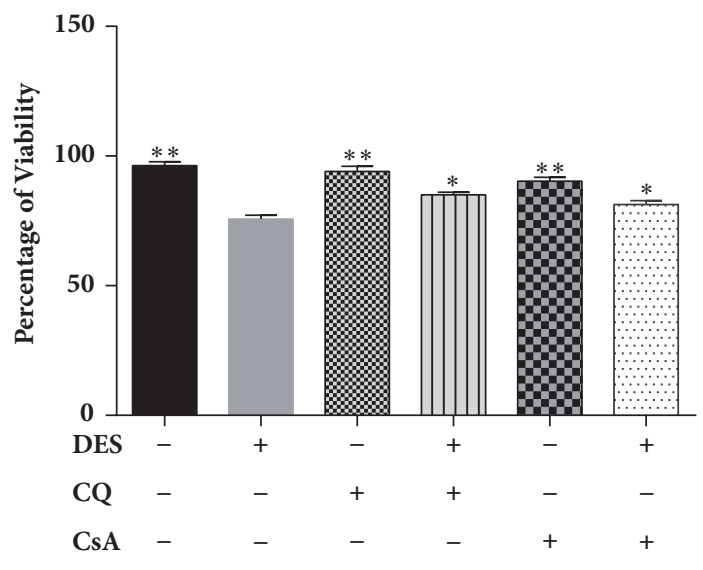

(d)

Figure 1: Continued. 

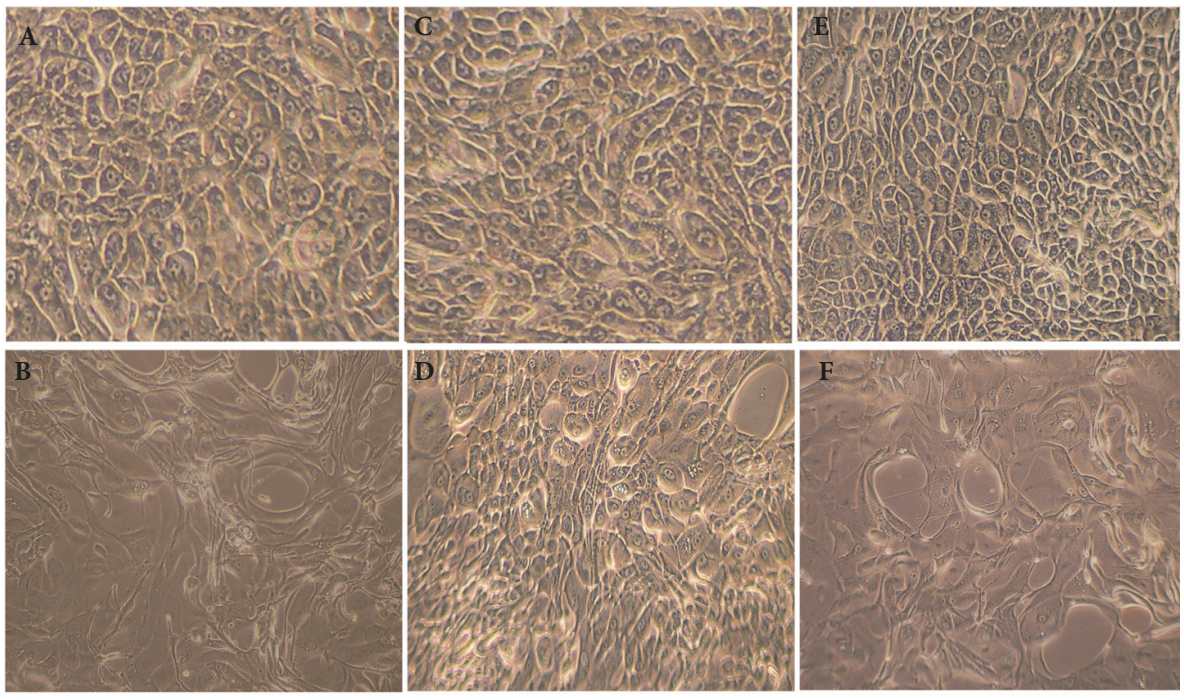

(e)

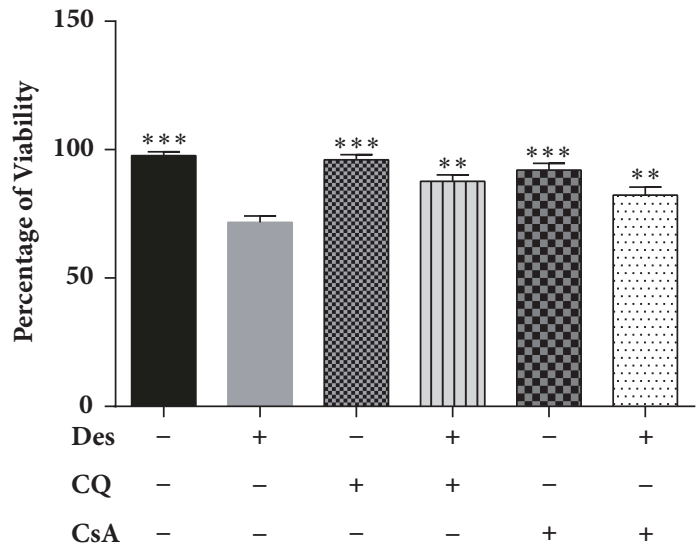

(f)

FIGURE 1: Morphological and viability analysis of HCE-T, Primary HCF, and HCE cells exposed to desiccation stress. (a) Bright field images of HCE-T cells exposed to desiccation stress, with and without chloroquine (CQ) /cyclosporine (CsA) treatment under the 10X. ((A) Non-desiccated/control HCE-T cells, (B) desiccated HCE-T cells, (C) desiccated cells treated with CQ, and (D) desiccated cells treated with CsA) (Figure 1(a)). (b) Percentage of cell viability of HCE-T cells exposed to desiccation cells with and without (CQ/CsA) treatment (Figure 1(b)). (c) Bright field images of primary HCF cells exposed to desiccation stress, with and without chloroquine (CQ)/cyclosporine (CsA) treatment under the 10X objective. ((A) Non-desiccated/control HCF cells, (B) desiccated HCF cells, (C) HCF cells treated with CQ, (D) desiccated HCF cells treated with CQ, (E) HCF cells treated with CsA, and (F) desiccated cells treated with CsA) (Figure 1(c)). (d) Percentage of cell viability of HCF cells exposed to desiccation cells with and without (CQ/CsA) treatment (Figure 1(d)). (e) Bright field images of primary HCE cells exposed to desiccation stress, with and without chloroquine (CQ)/cyclosporine (CsA) treatment under the 10X objective. ((A) Non-desiccated/control primary HCE cells, (B) desiccated primary HCE cells, (C) primary HCE cells treated with CQ, (D) desiccated cells treated with CQ, (E) primary HCE cells treated with CsA, and (F) desiccated cells treated with CsA (Figure 1(e)). (f) Percentage of cell viability of primary HCE cells exposed to desiccation stress with and without (CQ/ CsA) treatment (Figure $1(\mathrm{f})$ ). Data are the mean \pm SD, $\mathrm{n}$ $=3$; statistical significance was denoted $\left({ }^{*} \mathrm{p}<0.05,{ }^{* *} \mathrm{p}<0.01,{ }^{* * *} \mathrm{p}<0.001\right.$, and ns-nonsignificant as compared to desiccated cells). Note that --- is control, +-- are HCE/HCF cells exposed to desiccation (Des), -+- are HCE/HCF cells treated with chloroquine (CQ), ++- are desiccated $\mathrm{HCE} / \mathrm{HCF}$ cells treated with chloroquine (CQ), --+ are HCE/HCF cells treated with Cyclosporine (CsA), and -++ are desiccated HCE/HCF cells treated with Cyclosporine (CsA).

stress was evaluated by examining the inflammation and autophagy related molecular factors. We found that HCE$\mathrm{T}$ cells, primary HCF and HCE cells under desiccation stress exhibited $15-30 \%$ decrease in cell viability compared to control. Desiccation stress has been used as an experimental condition for studying the pathogenesis of dry eye and studies have reported that desiccation causes intracellular changes leading to apoptosis [21, 22]. Cytomorphological changes were noted in the corneal epithelium comprising changes in size of cells and the occurrence of goblet cells with tubular, tortuous chromatin during desiccation stress [23-25]. Similarly, we observed that HCE-T, primary HCF and HCE cells exposed to desiccation stress showed morphological changes in the cell size and shape compared to control. Dry 

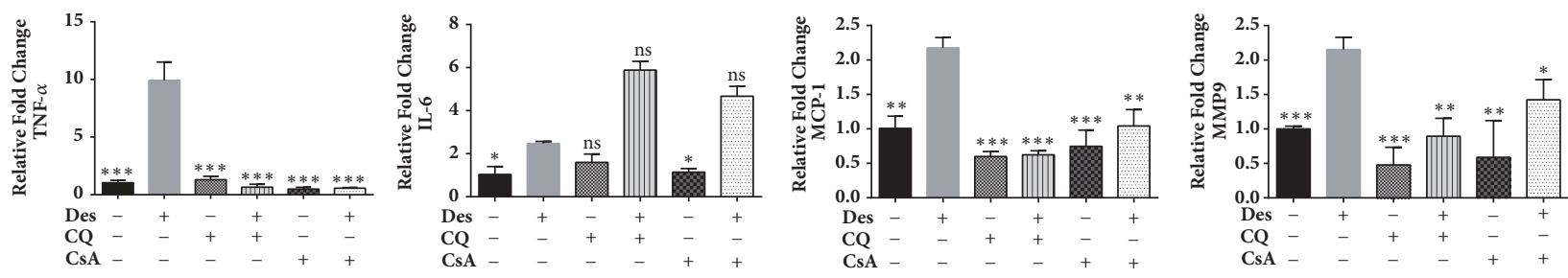

(a)
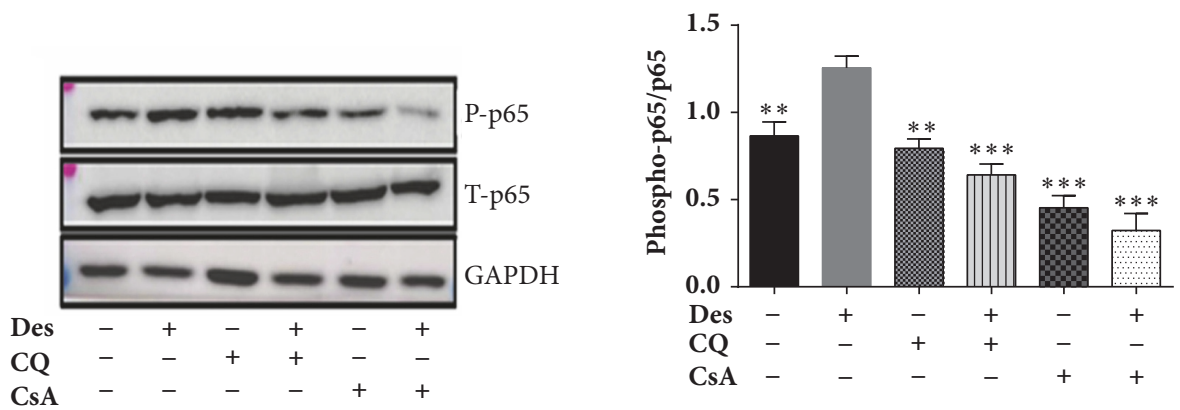

(b)
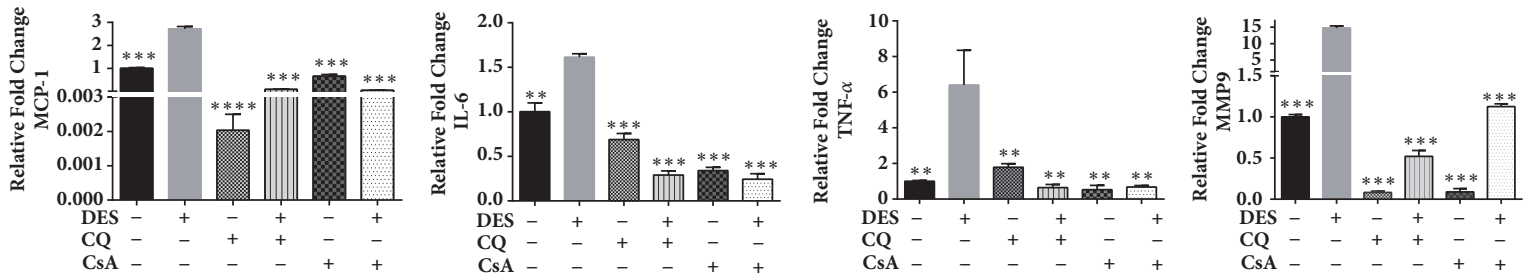

(c)
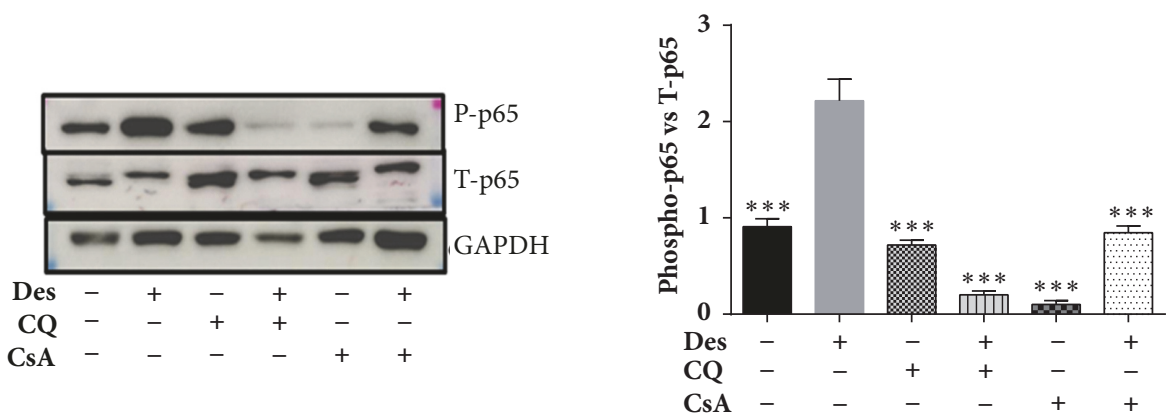

(d)

FIGURE 2: Expression of inflammatory related genes and NFKB pathway proteins in HCE-T and HCF cells under desiccation stress. (a) The mRNA expression levels of MCP-1, MMP-9, IL-6, and TNF- $\alpha$ in HCE-T cells under desiccation stress (Figure 2(a)). (b) Immunoblot shows the phosphorylation status of p65 in HCE-T cells exposed to desiccation stress, with and without CQ/CsA treatment. Densitometric analysis of the blots showed the ratios of total p65 and phosphorylated p65 at (Ser536) (Figure 2(b)). (c) The mRNA expression levels of MCP-1, MMP-9, IL-6, and TNF- $\alpha$ in HCF cells under desiccation stress (Figure 2(c)). (d) Immunoblot shows the phosphorylation status of p65 in HCF cells exposed to desiccation with and without CQ/CsA treatment. Densitometric analysis of the blots showed the ratios of total p65 and phosphorylated p65 at (Ser536) (Figure 2(d)). Data are the mean \pm SD, $n=3$; statistical significance was denoted $\left({ }^{*} \mathrm{p}<0.05,{ }^{* *} \mathrm{p}\right.$ $<0.01,{ }^{* * *} \mathrm{p}<0.001$, and ns- nonsignificant as compared to desiccated cells). Note that --- is control, +-- are HCE-T/HCF cells exposed to desiccation (Des), -+- are HCE-T/HCF cells treated with chloroquine (CQ), ++- are desiccated HCE-T/HCF cells treated with chloroquine (CQ), --+ are HCE-T/HCF cells treated with Cyclosporine (CsA) and -++ are desiccated HCE-T/HCF cells treated with cyclosporine (CsA).

eye disease is characterized by ocular inflammation; clinical studies have reported elevated levels of IL-1, IL- 6 , TNF- $\alpha$, and TGF- $\beta 1$ [26-28], along with MMP-9 in the tear film of dry eye patients $[29,30]$. In vitro and in vivo studies on HCE cells and mouse corneal epithelium cells have shown increased expression of IL-6, IL-8, TNF- $\alpha$, MMP's, and IL-8 levels on exposure to desiccation stress $[31,32]$. It was seen that desiccation stress in HCE-T cells led to an increase in the expression levels of IL- 6 , TNF- $\alpha$, MCP-1, and MMP9 genes compared to control, which is in agreement with previous findings [32]. In the present study, we found that desiccation stress induces inflammation in HCE-T and HCF 

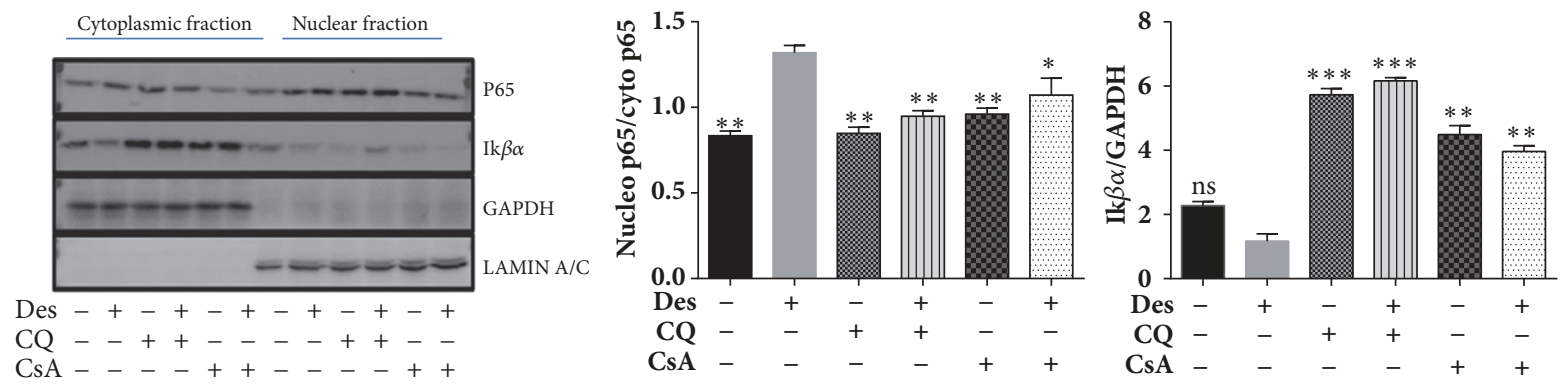

(a)
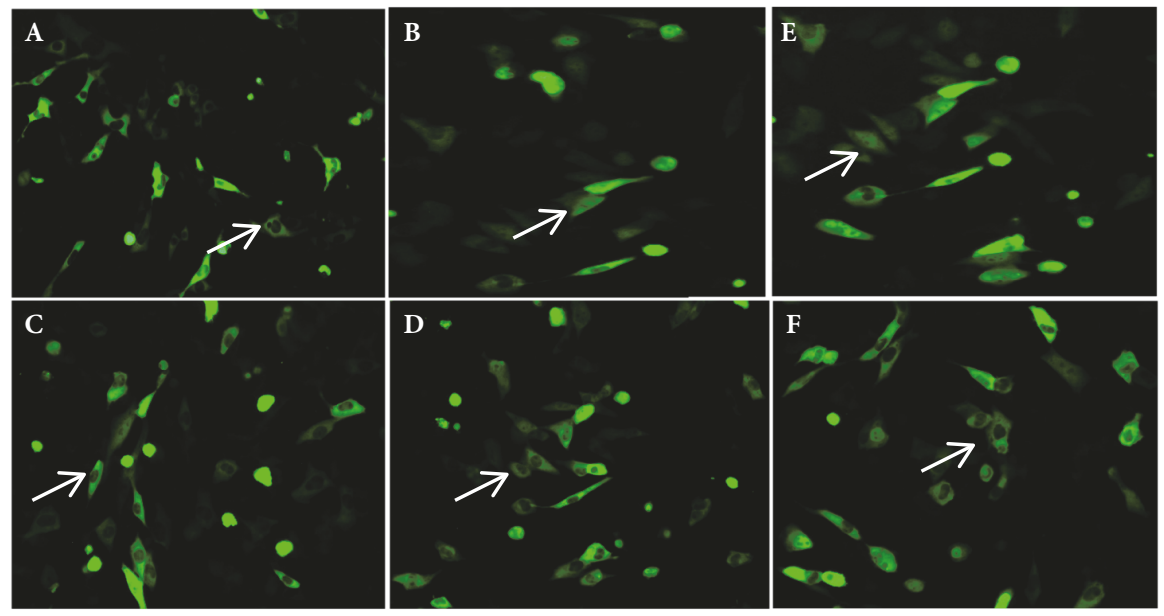

(b)

FIGURE 3: Expression of $\mathbf{p} 65$ and $\mathrm{I} \boldsymbol{\kappa} \mathrm{B} \boldsymbol{\alpha}$ proteins in HCE-T cells under desiccation stress. (a) Immunoblots of nuclear/cytoplasmic fractions shows protein expression levels of p65 (NFאB) and $\mathrm{I} \kappa \mathrm{B} \alpha$ in HCE-T cells exposed to desiccation stress (treated with or without CQ and CsA). Densitometric analysis of the blots shows the ratios of total p65 to $\mathrm{I} \kappa \mathrm{B} \alpha$ (Figure 3(a)). (b) GFP-RelA translocation images at 20X magnification of HCE-T cells under desiccation stress treated with/without CQ and CsA (Figure 3(b)). ((A) Non-desiccated/control HCE-T cells, (B) desiccated HCE-T cells, (C) desiccated cells treated with CQ, (D) desiccated HCE-T cells treated with CsA, (E) HCE-T cells treated with TNF- $\alpha(10 \mathrm{ng} / \mathrm{ml})$, and (F) HCE-T cells treated with TNF- $\alpha(10 \mathrm{ng} / \mathrm{ml})+C s A$. Data are the mean \pm SD values, $\mathrm{n}=3$, statistical significance was denoted $\left({ }^{*} \mathrm{p}<0.05,{ }^{* *} \mathrm{p}<0.01,{ }^{* * *} \mathrm{p}<0.001\right.$, ns- nonsignificant as compared to levels of desiccated cells). Note that --- is control, +-- HCET cells exposed to desiccation (Des), -+- HCE-T cells treated with chloroquine (CQ), ++- desiccated HCE-T cells treated with chloroquine (CQ), --+ HCE-T cells treated with cyclosporine (CsA), and -++ desiccated HCE-T cells treated with cyclosporine (CsA).

cells which was regulated through canonical NF- $\kappa$ B pathway. Activation and nuclear translocation of NF- $\kappa$ B/RelA leads to the transcription of downstream pro-inflammatory genes [33]. There was a significant increase in the phosphorylation level of $\mathrm{p} 65$ followed by its nuclear translocation in desiccated cells, which could have led to activation of the downstream targets IL6, TNF- $\alpha$, MMP-9, and MCP-1. Autophagy has been associated with inflammation [34] and studies have reported the induction of autophagy during desiccation stress as an adaptive response which leads to cell survival or cell death in yeast [35]. Increased expression of two major autophagy markers, LC3 (autophagosomes) and LAMP1 (lysosomes), was seen in HCE-T cells exposed to desiccation stress, which may indicate the induction of autophagy during desiccation, as an adaptive response.Further, it is well known that dephosphorylation of AKT/p70S6K is associated with mTOR mediated induction of autophagy [36]. Interestingly, we observed dephosphorylation in the levels of AKT/p70S6k in HCE-T cells exposed to desiccation stress, which may also suggest the induction of autophagy during desiccation. Additionally, induction of autophagy may also lead to autophagy mediated cell death, which requires regulators such as beclin1. Studies have reported that knockdown of beclin1 gene protects neuronal cells against ischemia indicating autophagy mediated cell death [37]. We found elevated levels of beclin 1 in desiccated HCE-T cells, which may indicate the possibility of autophagy mediated cell death as a consequence of desiccation stress. The increased number of autophagosomes (LC3) and lysosomes (LAMP1) in desiccated HCE-T cells treated with CQ suggest that there was no change in desiccation mediated autophagic flux [20]. On the other hand, this would be possible because the formulated concentration of CQ might not affect the autophagic flux rate in HCE-T cells under desiccation stress.

Choloroquine is used as an anti-inflammatory drug for treating chronic disease such as rheumatoid arthritis [5]. Experimental studies have illustrated that chloroquine blocks LPS induced expression of TNF- $\alpha$ and IL-6 in macrophages and PBMC's [38-40]. It was also found to reduce expression of IL-1 and cell-associated TNF- $\alpha$ in 

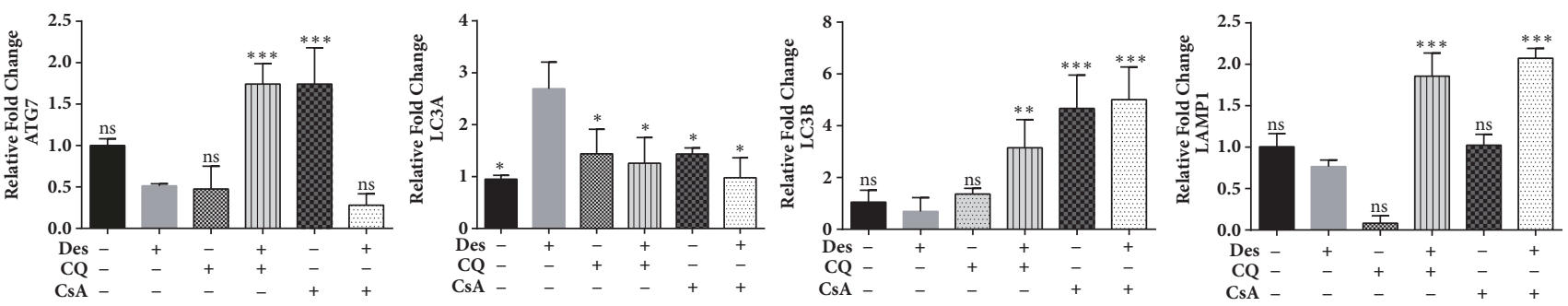

(a)
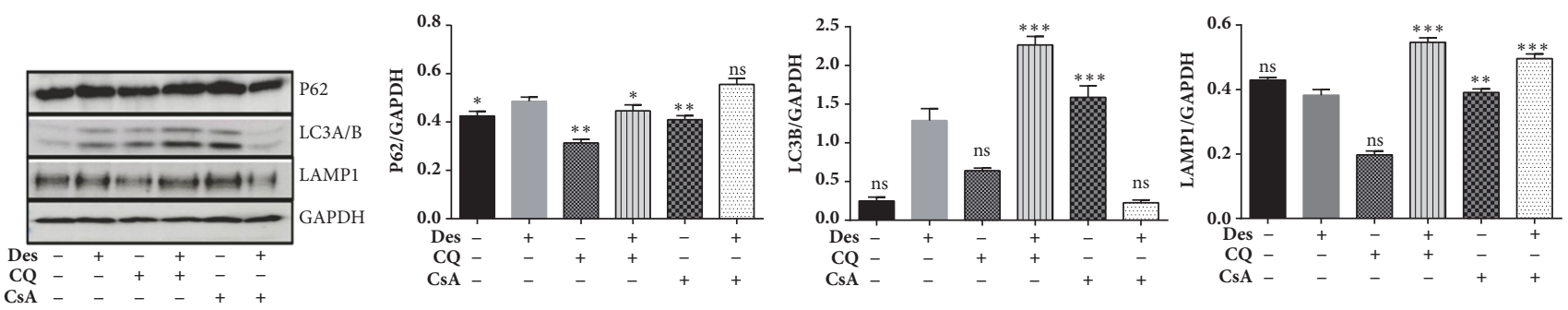

(b)
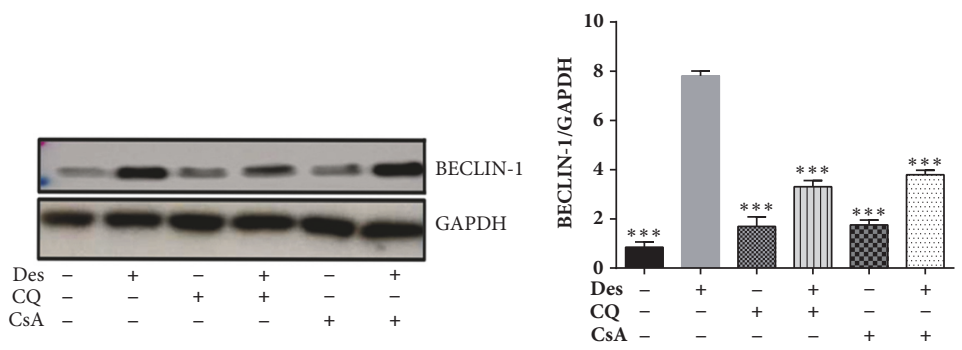

(c)

FIGURE 4: (a)-(c) Expression of autophagy related genes and proteins in HCE-T under desiccation stress. (a) The mRNA expression levels of LC3A, LC3B, ATG7, and LAMP1 in HCE-T cells exposed to desiccation stress, treated with and without CQ/CsA treatment normalized with $\beta$-actin (Figure 4(a)). (b) Immunoblot shows the protein levels of LC3, p62, and LAMP1 HCE-T cells exposed to desiccation stress and treated with and without CQ/CsA treatment (Figure 4(b)). Densitometric analysis of the blots showed the ratios of LAMP1, LC3-II and p62 to GAPDH. (c) Westernblot shows the expression levels of Beclin-1 protein in HCE-T cells exposed to desiccation stress and treated with and without CQ/CsA treatment (Figure 4(c)). Densitometric analysis of the blots showed the ratios of Beclin-1 to GAPDH. Data are the mean \pm $\mathrm{SD}$ values, $\mathrm{n}=3$, statistical significance denoted $\left({ }^{*} \mathrm{p}<0.05,{ }^{* *} \mathrm{p}<0.01,{ }^{* * *} \mathrm{p}<0.001\right.$, and ns- nonsignificant as compared to levels of desiccated cells). Note that --- is control, +-- HCE-T cells exposed to desiccation (Des), -+- HCE-T cells treated with chloroquine (CQ), ++- desiccated HCE-T cells treated with Chloroquine (CQ), --+ HCE-T cells treated with cyclosporine (CsA), and -++ desiccated HCE-T cells treated with cyclosporine (CsA).

LPS induced inflammation [41, 42]. Similarly, our results revealed that treatment with CQ decreased the expression levels of inflammatory genes TNF- $\alpha$, MCP-1 and MMP-9 in HCE-T and HCF cells exposed to desiccation stress. Our data additionally demonstrate that CQ regulates $\mathrm{NF} \kappa \mathrm{B}$ by inhibiting the phosphorylation and nuclear translocation of p65/RelA, thereby blocking the transcription of downstream targets.

Our data further reveals an increased phosphorylation levels of ERK1/2 and p38 proteins in HCE-T cells exposed to desiccation stress, which might be an adaptive response of HCE-T cells to desiccation stress. Studies have reported that activation of MAPK proteins- ERK1/2 and p38 during desiccation stress $[43,44]$. Increased phosphorylation of p38 in desiccated HCE-T cells might be involved in the reduced cell viability since it has been reported that prolonged phosphorylation of p38 leads to cell death in HEK-293 cells exposed to hyperosmolarity stress [45]. Interestingly, treatment with CQ reduced the phosphorylation levels of p38 thereby reducing cell death in HCE-T cells exposed to desiccation stress.

Induction of pro-survival pathways during desiccation stress helps mammalian cells to attain tolerance towards stress [46]. We observed that treatment of CQ was able increase the phosphorylation levels of AKT/p70S6k proteins thereby preventing apoptosis in HCE-T cells exposed to desiccation stress. Further, it has been shown that upstream (AKT) and downstream targets (p70S6k) of mTOR play a key role in regulating apoptosis and autophagy in UV induced cell death [47]. CQ acts as an anti-inflammatory agent through its lysomotrophic [48] or nonlysomotrophic activity [42]; henceforth in our future studies we would like to explore on the anti-inflammatory activity of the CQ is attributed to its lysomotrophic and nonlysomotrophic action. While it is a limitation of the present study, it would be interesting to analyse the effect of CQ preclinical and clinical 

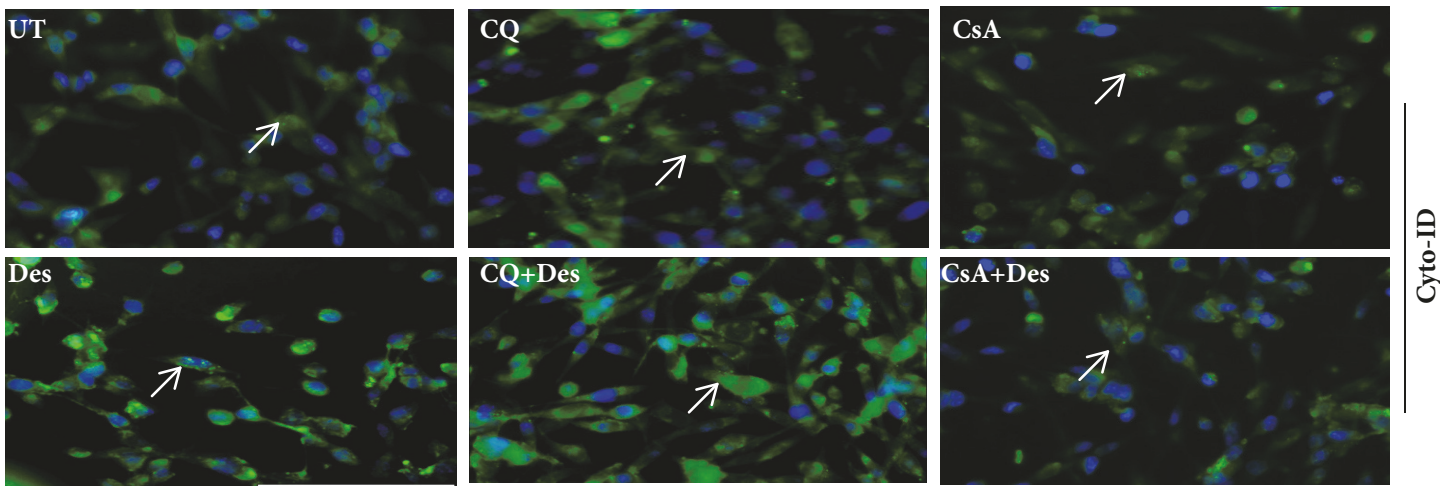

(a)
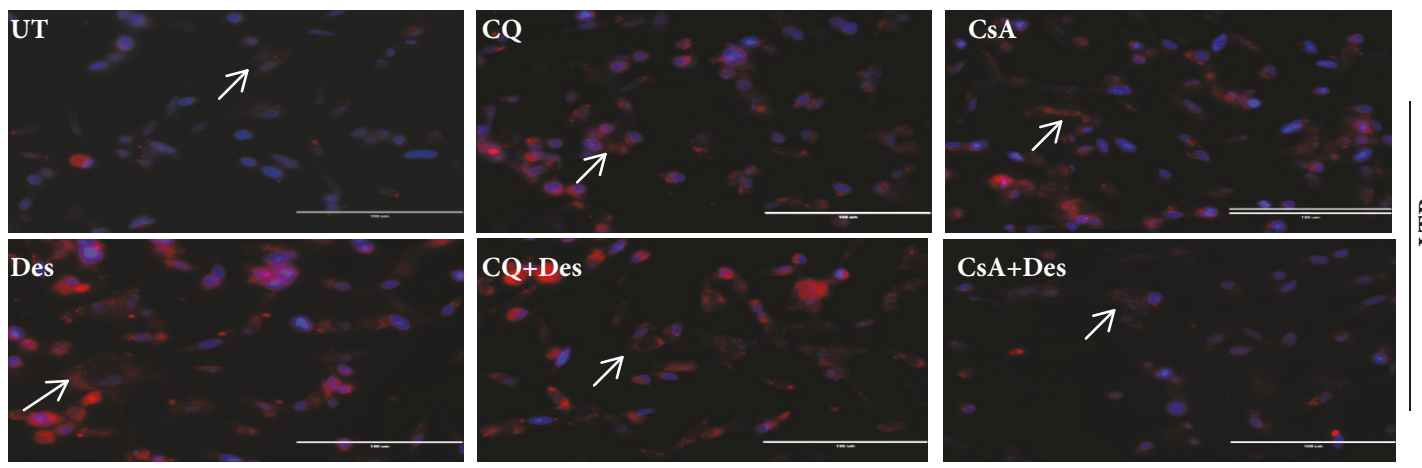

(b)
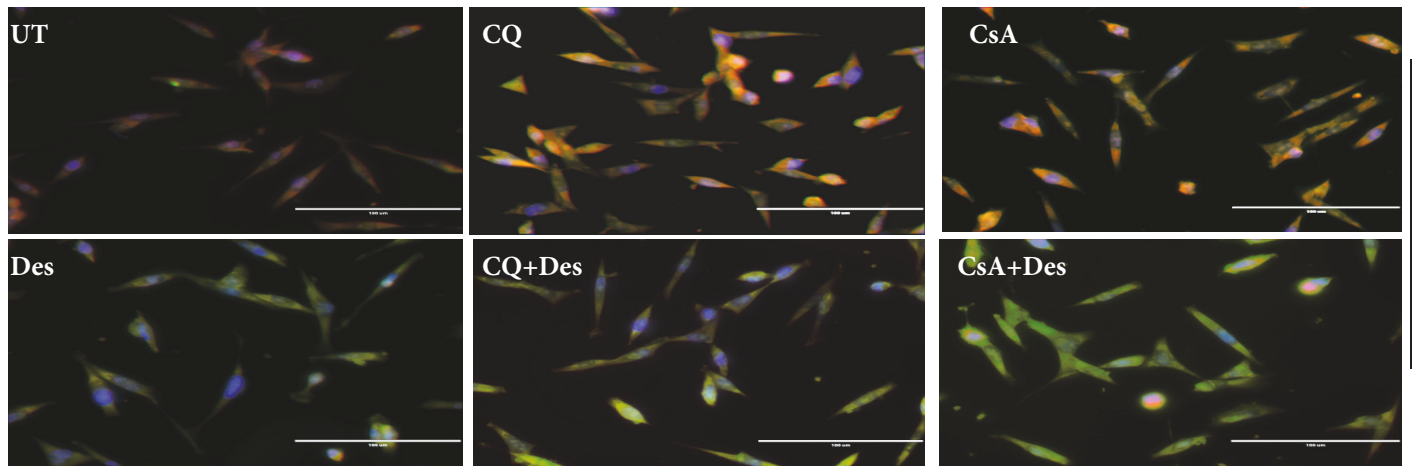

?

(c)

Figure 5: (a)-(c) Quantification of autophagosomes and lysosomes in desiccated HCE-T cells. (a) Cyto-Id staining for quantification of autophagosome staining in HCE-T cells under desiccation stress, with and without CQ/CsA treatment (Figure 5(a)). (b) LTR- lysotracker red staining to measure lysosome levels staining in HCE-T cells under desiccation stress, with and without CQ/CsA treatment (Figure 5(b)). (c) AO- Lysosomal $\mathrm{pH}$ assessed using acridine orange (AO) staining in HCE-T cells under desiccation stress, with and without CQ/CsA treatment (Figure 5(c)). UT- control or undesiccated cells, Des- HCE-T cells exposed to desiccation, CQ- HCE-T cells treated with chloroquine (CQ), CQ+Des- desiccated HCE-T cells treated with chloroquine (CQ), CsA- HCE-T cells treated with cyclosporine (CsA), and CsA+Desdesiccated HCE-T cells treated with cyclosporine (CsA).

studies, which may further validate the anti-inflammatory and cytoprotective effect of CQ.

It has been shown that CQ at high prolonged doses causes severe systemic and nonsystemic side effects, whereas the low does and application have not shown any side effects [11]. These side effects might be consequences of autophagic blocking activity of CQ at high doses. Therefore, we hypothesise that low concentrations CQ acts as an antiinflammatory agent without changes in autophagy dynamics in human corneal epithelial and fibroblast cells.

\section{Conclusion}

In conclusion, CQ protects human corneal cells from desiccation stress induced inflammation through its interaction with the canonical NFKB pathway. Activation of autophagy and cell death in HCE-T cells under desiccation stress might be mediated through the mTOR/MAPKinase and pathways. CQ regulated the phosphorylation MAPKinase and mTOR related proteins, thereby preventing desiccation stress induced cell death, without altering the autophagy 


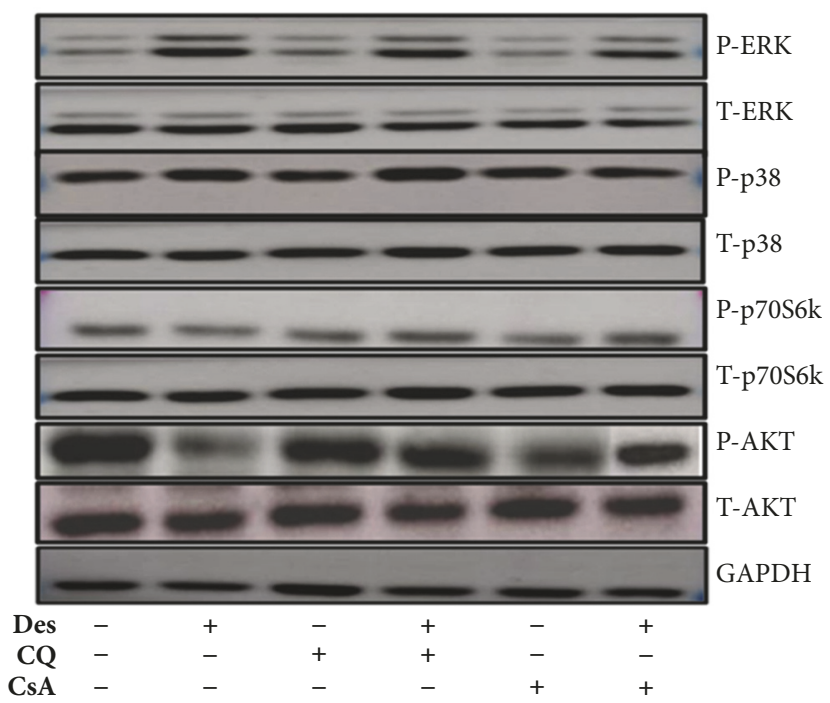

(a)
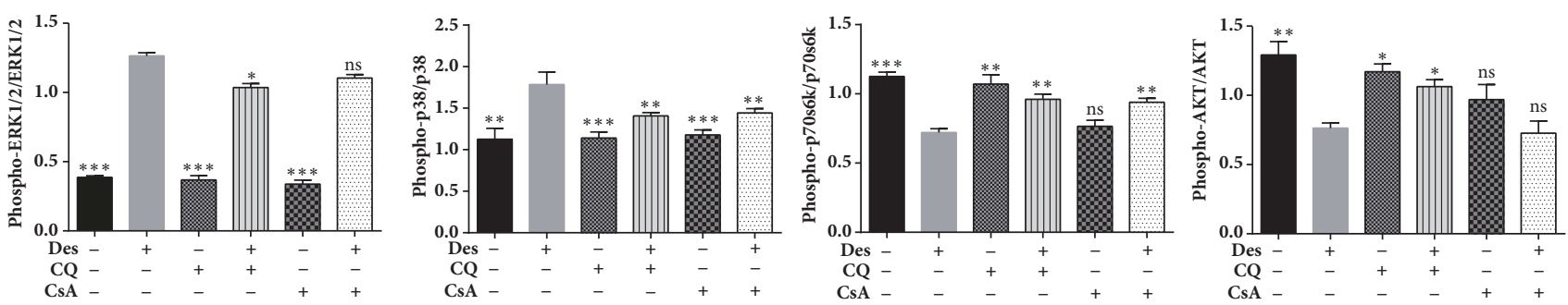

(b)

Figure 6: Phosphorylation levels of MAP kinase, AKT/p70S6kinase and AMPK proteins in HCE-T cells under desiccation stress. Immunoblot shows phosphorylated ERK1/2, p38, AKT and P70S6kinase, and AMPK (Figure 6). Densitometric analysis of the blots showed the ratios of phosphorylated AKT, p70s6kinase, ERK1/2 and p38 to AKT, p70s6kinase, ERK1/2, and p38. Data are the mean \pm SD values, $\mathrm{n}=$ 3 , statistical significance denoted $\left({ }^{*} \mathrm{p}<0.05,{ }^{* *} \mathrm{p}<0.01,{ }^{* * *} \mathrm{p}<0.001\right.$, and ns- nonsignificant as compared to desiccated cells). Note that --- is control, +-- HCE-T cells exposed to desiccation (Des), -+- HCE-T cells treated with chloroquine (CQ), ++- desiccated HCE-T cells treated with chloroquine (CQ), --+ HCE-T cells treated with cyclosporine (CsA), and -++ desiccated HCE-T cells treated with cyclosporine (CsA).

flux. These results suggest that CQ may be used as an alternate therapy for inflammation associated with dry eye disease.

\section{Abbreviations}

DED: Dry eye disease

CQ: Chloroquine

CsA: Cyclosporine.

\section{Data Availability}

The data used to support the findings of this study are available from the corresponding author upon request.

\section{Conflicts of Interest}

Authors declare no conflicts interest.

\section{Authors' Contributions}

Shivapriya Shivakumar and Trailokyanath Panigrahi have equal contributions.

\section{Acknowledgments}

The authors acknowledge FDC Ltd, Mumbai, India, and Narayana Nethralaya Foundation (NNF) for funding this study.

\section{Supplementary Materials}

Supplementary Figure 1: Cytotoxicity effect of CQ in HCE-T cells. Supplementary Figure 2: Immunostaining of Cytokeratin 3 in HCE cells. (Supplementary Materials)

\section{References}

[1] M. A. Lemp, C. Baudouin, J. Baum et al., "The definition and classification of dry eye disease: Report of the definition and classification subcommittee of the International Dry Eye WorkShop (2007)," The Ocular Surface, vol. 5, no. 2, pp. 75-92, 2007.

[2] M. E. Stern, J. Gao, T. A. Schwalb et al., "Conjunctival T-cell subpopulations in Sjogren's and non-Sjogren's patients with dry eye," Investigative Ophthalmology \& Visual Science, vol. 43, no. 8, pp. 2609-2614, 2002. 
[3] A. Solomon, D. Dursun, Z. Liu, Y. Xie, A. Macri, and S. C. Pflugfelder, "Pro- and anti-inflammatory forms of interleukin1 in the tear fluid and conjunctiva of patients with dry-eye disease," Investigative Ophthalmology \& Visual Science, vol. 42, no. 10, pp. 2283-2292, 2001.

[4] J. Čejková, T. Ardan, Z. Šimonová et al., "Nitric oxide synthase induction and cytotoxic nitrogen-related oxidant formation in conjunctival epithelium of dry eye (Sjögren's syndrome)," Nitric Oxide: Biology and Chemistry, vol. 17, no. 1, pp. 10-17, 2007.

[5] W. P. Arend and J.-M. Dayer, "Inhibition of the production and effects of interleukin-1 and tumor necrosis factor $\alpha$ in rheumatoid arthritis," Arthritis \& Rheumatism, vol. 38, no. 2, pp. 151-160, 1995.

[6] B. Bresnihan, J. M. Alvaro-Gracia, M. Cobby et al., "Treatment of rheumatoid arthritis with recombinant human interleukin-1 receptor antagonist," Arthritis \& Rheumatology, vol. 41, no. 12, pp. 2196-2204, 1998.

[7] E. H. S. Choy, D. A. Isenberg, T. Garrood et al., "Therapeutic benefit of blocking interleukin-6 activity with an anti-interleukin-6 receptor monoclonal antibody in rheumatoid arthritis: A randomized, double-blind, placebo-controlled, dose-escalation trial," Arthritis \& Rheumatology, vol. 46, no. 12, pp. 3143-3150, 2002.

[8] S. M. Weber, J.-M. Chen, and S. M. Levitz, "Inhibition of mitogen-activated protein kinase signaling by chloroquine," The Journal of Immunology, vol. 168, no. 10, pp. 5303-5309, 2002.

[9] S. Fougeray and N. Pallet, "Mechanisms and biological functions of autophagy in diseased and ageing kidneys," Nature Reviews Nephrology, vol. 11, no. 1, pp. 34-45, 2015.

[10] W. Chaabane, S. D. User, M. El-Gazzah et al., "Autophagy, apoptosis, mitoptosis and necrosis: interdependence between those pathways and effects on cancer," Archivum Immunologiae et Therapia Experimentalis, vol. 61, no. 1, pp. 43-58, 2013.

[11] R. B. Melles and M. F. Marmor, "Pericentral retinopathy and racial differences in hydroxychloroquine toxicity," Ophthalmology, vol. 122, no. 1, pp. 110-116, 2015.

[12] M. A. Al-Bari, "Chloroquine analogues in drug discovery: new directions of uses, mechanisms of actions and toxic manifestations from malaria to multifarious diseases," Journal of Antimicrobial Chemotherapy, 2015.

[13] P. J. Venables, "Management of patients presenting with Sjogren's syndrome," Best Practice \& Research Clinical Rheumatology, vol. 20, no. 4, pp. 791-807, 2006.

[14] A. A. Kruize, R. J. Hene, C. G. M. Kallenberg et al., "Hydroxychloroquine treatment for primary Sjogren's syndrome: A two year double blind crossover trial," Annals of the Rheumatic Diseases, vol. 52, no. 5, pp. 360-364, 1993.

[15] T. Into, T. Horie, M. Inomata et al., "Basal autophagy prevents autoactivation or enhancement of inflammatory signals by targeting monomeric MyD88," Scientific Reports, vol. 7, no. 1, 2017.

[16] K.-C. Yoon, I.-Y. Jeong, Y.-G. Park, and S.-Y. Yang, "Interleukin6 and tumor necrosis factor- $\alpha$ levels in tears of patients with dry eye syndrome," Cornea, vol. 26, no. 4, pp. 431-437, 2007.

[17] R. Shetty, S. Sethu, P. Chevour et al., "Lower Vitamin D Level and Distinct Tear Cytokine Profile Were Observed in Patients with Mild Dry Eye Signs but Exaggerated Symptoms," Translational Vision Science \& Technology, vol. 5, no. 6, p. 16, 2016.

[18] K. Dhamodaran, M. Subramani, N. Jeyabalan et al., "Characterization of ex vivo cultured limbal, conjunctival, and oral mucosal cells: a comparative study with implications in transplantation medicine," Molecular Vision, vol. 21, pp. 828-845, 2015.

[19] J. Wu, Y. Du, M. M. Mann, J. L. Funderburgh, and W. R. Wagner, "Corneal stromal stem cells versus corneal fibroblasts in generating structurally appropriate corneal stromal tissue," Experimental Eye Research, vol. 120, pp. 71-81, 2014.

[20] D. J. Klionsky, K. Abdelmohsen, A. Abe, M. J. Abedin, H. Abeliovich, A. Acevedo Arozena et al., "Guidelines for the use and interpretation of assays for monitoring autophagy (3rd edition)," Autophagy," in Autophagy, vol. 12, pp. 1-222, 3rd edition, 2016.

[21] M. Hovakimyan, T. Ramoth, M. Löbler et al., "Evaluation of protective effects of trehalose on desiccation of epithelial cells in three dimensional reconstructed human corneal epithelium," Current Eye Research, vol. 37, no. 11, pp. 982-989, 2012.

[22] T. Matsuo, "Trehalose protects corneal epithelial cells from death by drying," British Journal of Ophthalmology, vol. 85, no. 5, pp. 610-612, 2001.

[23] G. Geerling, S. MacLennan, and D. Hartwig, "Autologous serum eye drops for ocular surface disorders," British Journal of Ophthalmology, vol. 88, no. 11, pp. 1467-1474, 2004.

[24] J. Giebel, C. Woenckhaus, M. Fabian, and F. Tost, "Age-related differential expression of apoptosis-related genes in conjunctival epithelial cells," Acta Ophthalmologica Scandinavica, vol. 83, no. 4, pp. 471-476, 2005.

[25] F. Tost, "[Practical conjunctival cytology]," Der Ophthalmologe, vol. 96, no. 4, pp. 276-289, 1999.

[26] M. L. Massingale, X. Li, M. Vallabhajosyula, D. Chen, Y. Wei, and P. A. Asbell, "Analysis of inflammatory cytokines in the tears of dry eye patients," Cornea, vol. 28, no. 9, pp. 1023-1027, 2009.

[27] A. Enriquez-de-Salamanca, E. Castellanos, M. E. Stern et al., "Tear cytokine and chemokine analysis and clinical correlations in evaporative-type dry eye disease," Molecular Vision, vol. 16, pp. 862-873, 2010.

[28] S. C. Pflugfelder, D. Jones, Z. Ji, A. Afonso, and D. Monroy, "Altered cytokine balance in the tear fluid and conjunctiva of patients with Sjogren's syndrome keratoconjunctivitis sicca," Current Eye Research, vol. 19, no. 3, pp. 201-211, 1999.

[29] S. Chotikavanich, C. S. de Paiva, D. Q. Li et al., "Production and activity of matrix metalloproteinase- 9 on the ocular surface increase in dysfunctional tear syndrome," Investigative Ophthalmology \& Visual Science, vol. 50, no. 7, pp. 3203-3209, 2009.

[30] A. Acera, G. Rocha, E. Vecino, I. Lema, and J. A. Durán, "Inflammatory markers in the tears of patients with ocular surface disease," Ophthalmic Research, vol. 40, no. 6, pp. 315321, 2008.

[31] R. M. Corrales, M. E. Stern, C. S. De Paiva, J. Welch, D.-Q. Li, and S. C. Pflugfelder, "Desiccating stress stimulates expression of matrix metalloproteinases by the corneal epithelium," Investigative Ophthalmology \& Visual Science, vol. 47, no. 8, pp. 32933302, 2006.

[32] A. Higuchi, T. Kawakita, and K. Tsubota, "IL-6 induction in desiccated corneal epithelium in vitro and in vivo," Molecular Vision, vol. 17, pp. 2400-2406, 2011.

[33] A. S. Baldwin Jr., "The NF- $\kappa$ B and $I \kappa$ B proteins: new discoveries and insights," Annual Review of Immunology, vol. 14, pp. 649683, 1996.

[34] M. Qian, X. Fang, and X. Wang, "Autophagy and inflammation," linical and Translational Medicine, vol. 6, no. 1, 2017.

[35] S. Ratnakumar, A. Hesketh, K. Gkargkas et al., "Phenomic and transcriptomic analyses reveal that autophagy plays a major 
role in desiccation tolerance in Saccharomyces cerevisiae," Molecular BioSystems, vol. 7, no. 1, pp. 139-149, 2011.

[36] R. Shetty, A. Sharma, N. Pahuja et al., "Oxidative stress induces dysregulated autophagy in corneal epithelium of keratoconus patients," PLoS ONE, vol. 12, no. 9, 2017.

[37] S. Xing, Y. Zhang, J. Li et al., "Beclin 1 knockdown inhibits autophagic activation and prevents the secondary neurodegenerative damage in the ipsilateral thalamus following focal cerebral infarction," Autophagy, vol. 8, no. 1, pp. 63-76, 2012.

[38] W. Ertel, M. H. Morrison, A. Ayala, and I. H. Chaudry, "Chloroquine attenuates hemorrhagic shock-induced suppression of Kupffer cell antigen presentation and major histocompatibility complex class II antigen expression through blockade of tumor necrosis factor and prostaglandin release," Blood, vol. 78, no. 7, pp. 1781-1788, 1991.

[39] S. Picot, F. Peyron, A. Donadille, J.-P. Vuillez, G. Barbe, and P. Ambroise-Thomas, "Chloroquine-induced inhibition of the production of TNF, but not of IL-6, is affected by disruption of iron metabolism," The Journal of Immunology, vol. 80, no. 1, pp. 127-133, 1993.

[40] B. E. van den, B. A. Borne, H. H. de Rooij, S. le Cessie, and C. L. Verweij, "Chloroquine and hydroxychloroquine equally affect tumor necrosis factor-alpha, interleukin 6, and interferongamma production by peripheral blood mononuclear cells," The Journal of Rheumatology, vol. 24, no. 1, pp. 55-60, 1997.

[41] I. Karres, J.-P. Kremer, I. Dietl, U. Steckholzer, M. Jochum, and W. Ertel, "Chloroquine inhibits proinflammatory cytokine release into human whole blood," American Journal of Physiology-Regulatory, Integrative and Comparative Physiology, vol. 274, no. 4, pp. R1058-R1064, 1998.

[42] S. M. Weber and S. M. Levitz, "Chloroquine interferes with lipopolysaccharide-induced TNF- $\alpha$ gene expression by a nonlysosomotropic mechanism," The Journal of Immunology, vol. 165, no. 3, pp. 1534-1540, 2000.

[43] L. Chang and M. Karin, "Mammalian MAP kinase signalling cascades," Nature, vol. 410, no. 6824, pp. 37-40, 2001.

[44] K. J. Cowan and K. B. Storey, "Mitogen-activated protein kinases: new signaling pathways functioning in cellular responses to environmental stress," Journal of Experimental Biology, vol. 206, no. 7, pp. 1107-1115, 2003.

[45] Z. Huang and A. Tunnacliffe, "Response of human cells to desiccation: Comparison with hyperosmotic strees response," The Journal of Physiology, vol. 558, no. 1, pp. 181-191, 2004.

[46] B. L. Bennett, D. T. Sasaki, B. W. Murray et al., "SP600125, an anthrapyrazolone inhibitor of Jun N-terminal kinase," Proceedings of the National Acadamy of Sciences of the United States of America, vol. 98, no. 24, pp. 13681-13686, 2001.

[47] E. Strozyk and D. Kulms, "The role of AKT/mTOR pathway in stress response to UV-irradiation: Implication in skin carcinogenesis by regulation of apoptosis, autophagy and senescence," International Journal of Molecular Sciences, vol. 14, no. 8, pp. 15260-15285, 2013.

[48] J. Park, D. Kwon, C. Choi, J.-W. Oh, and E. N. Benveniste, "Chloroquine induces activation of nuclear factor- $\kappa \mathrm{B}$ and subsequent expression of pro-inflammatory cytokines by human astroglial cells," Journal of Neurochemistry, vol. 84, no. 6, pp. 1266-1274, 2003. 


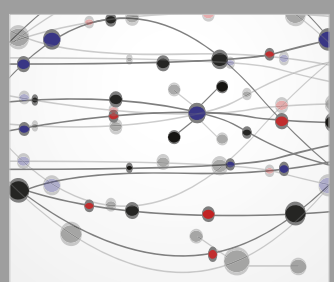

The Scientific World Journal
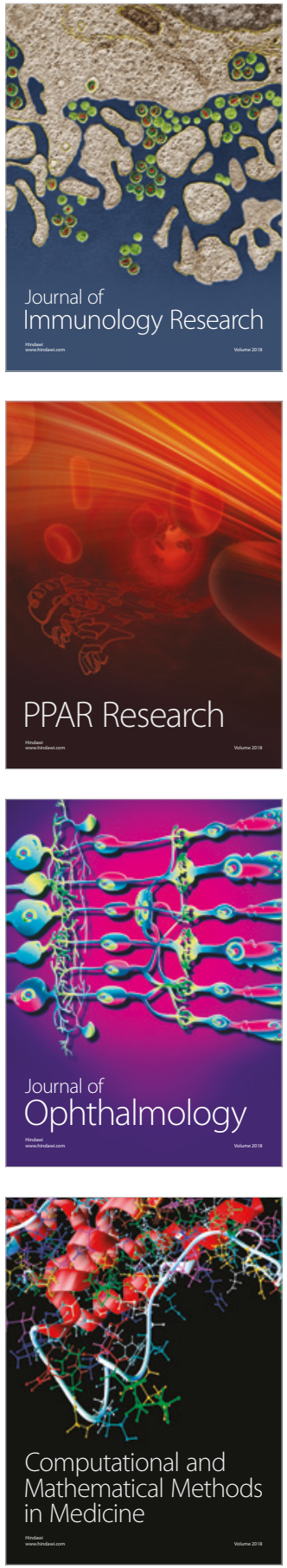

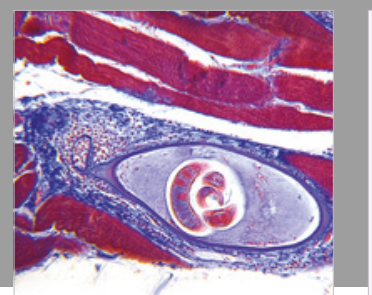

Gastroenterology Research and Practice

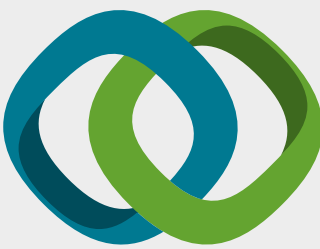

\section{Hindawi}

Submit your manuscripts at

www.hindawi.com
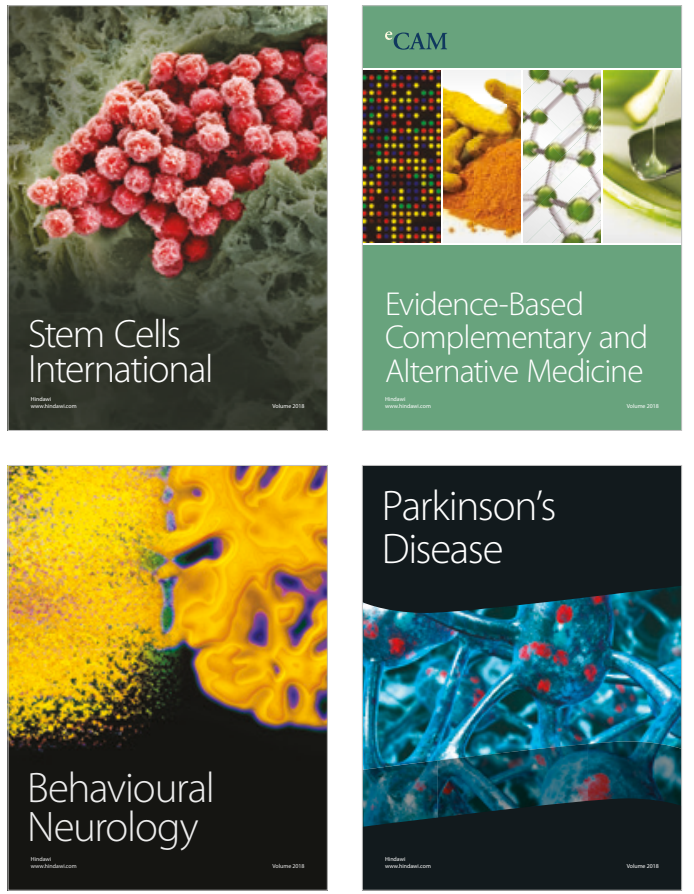

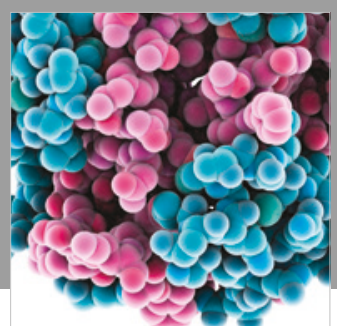

ournal of

Diabetes Research

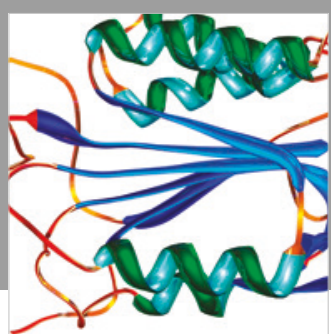

Disease Markers
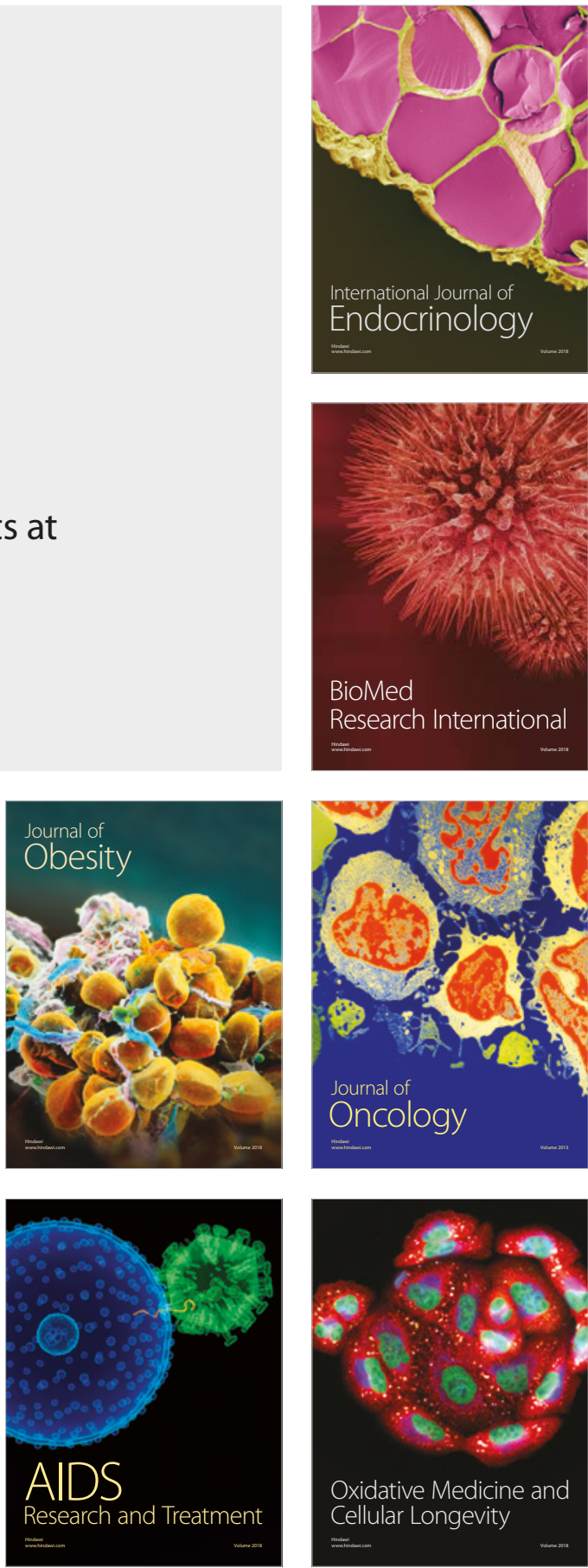